\title{
Socioeconomic inequality in intermittent preventive treatment using Sulphadoxine pyrimethamine among pregnant women in Nigeria
}

Fatima Mahmud Muhammad ${ }^{1}$, Reza Majdzadeh², Saharnaz Nedjat ${ }^{1}$, Haniye Sadat Sajadi ${ }^{3}$ and Mahboubeh Parsaeian ${ }^{1 *}$ (D)

\begin{abstract}
Background: Intermittent preventive treatment using Sulphadoxine pyrimethamine (IPTp-SP) for malaria prevention is recommended for all pregnant women in malaria endemic areas. However, there is limited evidence on the level of socioeconomic inequality in IPTp-SP use among pregnant women in Nigeria. Thus, this study aimed to determine the level of socioeconomic inequality in IPTp-SP use among pregnant women in Nigeria and to decompose it into its contributing factors.

Methods: A secondary data analysis of Nigerian demographic and health survey of 2018 was conducted. A sample of 21,621 pregnant women aged between 15 and 49 years and had live birth in the previous 2 years before the survey were included in this analysis. The study participants were recruited based on a stratified two-stage cluster sampling method. Socioeconomic inequality was decomposed into its contributing factors by concentration index.

Result: Totally $63.6 \%$ of pregnant women took at least one dose of IPTp-SP prophylaxis. Among IPTp-SP users, $35.1 \%$ took one dose, 38.6\% took two doses and 26.2\% took three doses and more. Based on both concentration index of 0.180 ( $p$-value $=<0.001,95 \%$ Cl: 0.176 to 0.183 ) and Erreyger's normalization concentration index 0.280 ( $p$ value $=<0.001,95 \% \mathrm{Cl}: 0.251$ to 0.309$)$, the IPTp-SP utilization was pro-rich. The largest contributors to the inequality in IPTP-SP uptake were wealth index (47.81\%) and educational status (28.66\%).

Conclusion: Our findings showed that IPTp-SP use was pro-rich in Nigeria. Wealth index and educational status were the factors that significantly contributed to the inequality. The disparities could be reduced through free IPTp service expansion by targeting pregnant women from low socioeconomic status.
\end{abstract}

Keywords: Malaria, Intermittent preventive treatment, Socioeconomic inequality, Decomposition analysis, Nigeria

\footnotetext{
* Correspondence: mahbobehparsaeian@yahoo.com

'Department of Epidemiology \& Biostatistics, School of Public Health, Tehran University of Medical Sciences, Tehran, Iran

Full list of author information is available at the end of the article

C C The Author(s). 2020 Open Access This article is licensed under a Creative Commons Attribution 4.0 International License, which permits use, sharing, adaptation, distribution and reproduction in any medium or format, as long as you give appropriate credit to the original author(s) and the source, provide a link to the Creative Commons licence, and indicate if changes were made. The images or other third party material in this article are included in the article's Creative Commons licence, unless indicated otherwise in a credit line to the material. If material is not included in the article's Creative Commons licence and your intended use is not permitted by statutory regulation or exceeds the permitted use, you will need to obtain permission directly from the copyright holder. To view a copy of this licence, visit http://creativecommons.org/licenses/by/4.0/. The Creative Commons Public Domain Dedication waiver (http://creativecommons.org/publicdomain/zero/1.0/) applies to the data made available in this article, unless otherwise stated in a credit line to the data.
} 


\section{Background}

Malaria is one of the most public health problems, especially among children and pregnant women in low and middle income countries [1]. An estimated 11 million pregnant women across 38 countries in the sub-Saharan Africa region were infected with malaria in 2018 [2]. This makes malaria infection during pregnancy a significant public health problem (i.e., 29\% of all pregnancies) [2], with substantial risks like maternal anemia, placental accumulation of parasite, low birth weight (LBW) and intrauterine growth retardation (IUGR), congenital infection and infant mortality (IM) [3, 4].

Nigeria is one of the countries bearing the highest burden of malaria. The prevalence of malaria in pregnant women in the country ranges from 19.7 to $72.0 \%[5,6]$. Further, it is a major cause of morbidity and mortality in the country [7].

The World Health Organization (WHO) recommends Intermittent Preventive Treatment in pregnancy (IPTp) in moderate to high malaria transmission areas in Africa [4]. However, considerable proportion of pregnant women do not use IPTp in Nigeria. For example, according to the Malaria indicator survey of 2018 revealed that $64 \%$ of women took IPTp [5].

Previous study conducted in Nigeria revealed a connection between malaria and poverty [6]. For example, women living in poorest household are less likely to report increased use of IPT compared to women from the richest household [8, 9]. As a result, Inequity in health service is unacceptable and unfair [10] and should be removed through free service expansion to the underserved population. Inequality is frequently assessed based on socioeconomic status that is measured in asset-based wealth quintiles, residence, sex, age and ethnicity [11].

While recent studies have reported inequalities related to malaria prevention especially in the use and ownership of mosquito nets, $[12,13]$, little exist explaining the inequalities in relation to the IPTp use among pregnant women. In this study, we assessed the factors contributing to the inequality in IPTp-SP use among pregnant women in Nigeria, and decomposed the socioeconomic inequality into its contributing factors. We hope findings of the study will contribute to reversing the burden of malaria in Nigeria, and beyond especially in the WHO African Region which carries a disproportionately greater share of the global malaria burden.

\section{Methods}

\section{Study design and participants}

The data for this study is the 2018 Nigeria Demographic and Health Survey (DHS) which is the fifth and the most recent survey implemented in the country by the DHS. Data collection was done from 14 August to 29 December
2018. The sampling frame used for the cross-sectional survey was generated from the results of the 2006 Population and Housing Census of Nigeria, the most recent census of Nigeria. The sample was subsequently selected using a stratified two-stage cluster design. Stratification was achieved by separating each of the 36 states and the Federal Capital Territory into urban and rural areas. In the first stage, 1400 enumeration areas were selected randomly with probability proportional to the enumeration area size. The primary sampling unit (PSU), referred to as a cluster, is defined on the basis of enumeration areas from the 2006 census frame. In each cluster, 30 households were randomly selected and all the women aged 15-49 who are either permanent residents or visitors present in the households were eligible to be interviewed. A questionnaire was used to interview all eligible women. Totally 21,621 women responded to question on IPTp use during pregnancy 2 years preceding the survey. Thus these women were used for the analysis of this study. More information on the survey methodology is available in the NDHS 2018 final report [14].

\section{Variable definition}

The outcome variable of this study was use of IPTp at least one dose among pregnant women. Independent variables included in the analysis were age, educational status, marital status, place of residence, wealth index, region, number of antenatal care visits and parity (see Supplementary Table 1). The wealth index is a composite measure of a household's cumulative living standard constructed using principal component analysis (PCA) as a proxy for socioeconomic status. Households were given scores based on the number and kinds of consumer goods they own, ranging from a television to a bicycle or car, and housing characteristics such as source of drinking water, toilet facilities, and flooring materials. The wealth index ranks each person in the population by their score and then divides the ranking into five equal parts, from quintile one (lowest-poorest) to quintile five (highest-wealthiest), each having approximately $20 \%$ of the population. Details could be accessed at DHS guide [15].

\section{Statistical analysis}

The main measures of inequality were concentration curve and concentration index [16]. The concentration curve shows the cumulative percentage of the health outcome (IPTp use) on the y-axis against cumulative percentage of the population in the $\mathrm{x}$-axis, ranked by the wealth index from the poorest to the richest. The curve will appear linear if all women irrespective of their wealth status have exactly the same value of the IPTp use. When the curve lies below the diagonal line it is pro-rich and above it indicates the pro poor inequality. 
The concentration index is defined as twice the area between the concentration curve and the line of equality (the 45-degree line).

Since the outcome variable was binary we used the Erreyger's normalized concentration index as preferred over the conventional concentration index [17]. Refer below:

$$
E(h)=4=\frac{\mu}{b_{h}-a_{h}} \mathrm{C}(\mathrm{h})
$$

Where $b_{h}$ and $a_{h}$ are the maximum and minimum of the health variable.

\section{Decomposition analysis}

Decomposition analysis method was proposed by Wagstaff et al. [16] to break down the socioeconomic inequality into its determinants. It also estimates how determinants proportionally contribute to inequality (e.g. the gap between poor and rich) in a health variable. We applied a generalized linear model for binomial distribution with identity link function for linking IPTp intake (y) to the set of $\mathrm{k}$ determinants $\left(\mathrm{X}_{\mathrm{k}}\right)$ [18] because it considers the structure of IPTp. By this method, the estimates do not vary with the choice of the reference group (yes or no). These render the model appropriate for our analysis. Decomposition analysis was used to break down the use of IPTp-SP. Due to the non-proportional allocation of the sample to the different states and possible difference in response rate, all analyses where weighted and adjusted for the design effect. Statistical analysis was conducted using STATA version 14 . Significance level was set at $p \leq 0.05$.

\section{Result}

The socio-demographic characteristics of respondents are given in Table 1 . The mean age of the respondents was 29 years $(\mathrm{SD}=9.70)$. The majority of the respondents (64.7\%) were rural dwellers and 9498 (43.9\%) with no education. Eighty-nine percent of the respondents received IPTp from antenatal care. The overall use of IPTp-SP among the women was 63.6\%. Among IPTp users, $35.1 \%$ took one dose, $38.6 \%$ took two doses and 26.2 took three doses and more. The adjusted associations between IPTp use and its determinants are shown in Table 2. Women with higher educational status [Adjusted OR $(95 \% \mathrm{CI})$ : 1.35 (1.14 to 1.60$) \quad p$-value $=<$ 0.001 ], being from the richest quintile [Adjusted OR (95\% CI): 2.32 (1.99 to 2.72 ) $p$-value $=<0.001]$, attending 4 or more antenatal visits [Adjusted OR (95\% CI): 14.66 (13.42 to 16.02) increased the probability of IPTp use. Age group, place of residency, parity and marital status showed no significant association. The Mean intake of Intermittent preventive treatment using Sulphadoxine Pyrimethamine (IPTp-SP) is presented in Fig. 1.

\section{Inequality in IPTp use}

IPTp use was pro-rich (Fig. 2) and the concentration index was $0.180 \quad(p$-value <0.001) (95\% CI:0.176 to 0.183). The Erreyger's normalized concentration index was 0.280 ( $p$-value< 0.001$) \quad(95 \% \mathrm{CI}: 0.251$ to 0.309$)$ which was significantly different from zero. Wealth index was the main contributor of IPTp use related inequality (47.81) followed by educational status (28.66) (Table 3). Positive and negative signs of the percentage contributed shows the inequality concentrated either in the poorest or richest women (Table 3).

\section{Discussion}

The results of the current study indicated disproportionate concentration of IPTp-SP intake was pro-rich. Four or more antenatal visit and education status were significantly associated with IPTp utilization in the adjusted odds ratio. This study shows that the pregnant women who took at least one or more doses of IPTp were 63.6\%. Among IPTp users, 35.1\% took one dose, $38.6 \%$ took two doses and 26.2 took three doses and more. As recommended by WHO, pregnant women should receive at least 3 doses of Sulphadoxine pyrimethamine, which was revised to a monthly administration during pregnancy [19], necessitating the need to increase its access. Recent studies in Ghana and Malawi reported three or more doses to be 64.5 and $70.2 \%$, respectively [20, 21]. Although the coverage of at least one dose of IPTp use has increased from $27 \%$ in 2013 to $64 \%$ in 2018, the coverage of three or more doses is much lower than other studies [14]. Even for the uptake of at least one dose of IPTp, the Nigerian Demographic \& Health Survey reports variation among pregnant women in urban and rural areas $(72.6 \& 58.0 \%$ respectively) [14].

The value of the concentration index of IPTp intake was 0.180 , indicating an increased use of IPTp among the rich. Further, decomposition of IPTp revealed that the variables wealth index and the level of education as the main contributors. On the other hand, age, marital status, place of residence, region and parity had insignificant influence to the observed socioeconomic inequality. Another study reported from earlier work in Nigeria, using only the concentration index to assess inequality, also showed the use of IPTp utilization as pro-rich [13]. This finding was comparable with the study reported from Kenya [22] which shows that poor individuals were less likely to use any kind of antimalarial drugs for pregnant women. In other studies, in some developing countries, IPTp use during pregnancy was concentrated among women in the richest households [8, 23, 24].

In contrast, the study reported by Mathanga et al. [12] revealed no inequality between pregnant women on 
Table 1 Socio-demographic characteristics of women aged 15-49 years who had a live birth 2 years preceding the survey, by intake of one dose of 1PTp

\begin{tabular}{|c|c|c|c|c|}
\hline \multirow[t]{2}{*}{ Variables } & & \multirow[t]{2}{*}{ N (\%) } & \multicolumn{2}{|l|}{$\mathrm{IPT}^{\S} \mathrm{n}(\%)$} \\
\hline & & & Yes & No \\
\hline \multirow[t]{4}{*}{ Age group } & $15-24$ & $5362(24.79)$ & $3222(60.09)$ & $2140(39.91)$ \\
\hline & $25-34$ & $10,197(47.16)$ & $6607(64.79)$ & $3590(35.21)$ \\
\hline & $35-44$ & $5357(24.77)$ & $3453(64.46)$ & $1904(35.54)$ \\
\hline & $\geq 45$ & 705 (3.26) & $423(60.00)$ & $282(40.00)$ \\
\hline \multirow[t]{4}{*}{ Educational status } & No education & 9498 (43.92) & $4862(51.18)$ & $4636(48.81)$ \\
\hline & Primary & $3373(15.60)$ & $2232(66.17)$ & $5162(33.83)$ \\
\hline & Secondary & $6973(32.25)$ & $5162(74.03)$ & $1811(25.97)$ \\
\hline & Higher & $1777(8.21)$ & $1449(81.54)$ & $328(18.46)$ \\
\hline \multirow[t]{3}{*}{ Marital Status } & Never Married & $600(2.77)$ & $378(63.00)$ & $222(37.00)$ \\
\hline & Married & $20,259(93.70)$ & $12,821(63.29)$ & $7438(36.71)$ \\
\hline & Separated & $762(3.52)$ & $506(66.40)$ & $256(33.60)$ \\
\hline \multirow[t]{2}{*}{ Place of residence } & Urban & $7634(35.30)$ & 5559 (72.82) & $2075(27.18)$ \\
\hline & Rural & $13,987(64.69)$ & $8146(58.24)$ & $5841(41.76)$ \\
\hline \multirow[t]{5}{*}{ Wealth index } & Poorest & $5007(23.15)$ & $2368(47.29)$ & $2639(52.71)$ \\
\hline & Poorer & $4865(22.50)$ & $2686(55.21)$ & $2179(44.79)$ \\
\hline & Middle & $4549(21.03)$ & $3072(67.53)$ & $1477(32.47)$ \\
\hline & Richer & $3986(18.43)$ & $2990(75.01)$ & $996(24.99)$ \\
\hline & Richest & $3214(14.86)$ & $2589(80.55)$ & $625(19.45)$ \\
\hline \multirow[t]{6}{*}{ Region } & North central & $3844(17.77)$ & $2245(58.40)$ & $1599(41.60)$ \\
\hline & North east & $4502(20.82)$ & $2827(62.79)$ & $1675(37.21)$ \\
\hline & North west & $6297(29.12)$ & $3678(58.41)$ & $2619(41.59)$ \\
\hline & South east & $2340(10.82)$ & 1827 (78.08) & $513(21.92)$ \\
\hline & South south & $2108(9.74)$ & 1481 (70.26) & $627(29.74)$ \\
\hline & South west & $2530(11.70)$ & 1647 (65.010) & $883(34.90)$ \\
\hline \multirow[t]{3}{*}{ ANC ${ }^{a}$ visits } & No visits & $5630(26.03)$ & 1158 (20.57) & $4472(79.43)$ \\
\hline & $<4$ times & $3778(17.47)$ & 2745 (72.66) & $1033(27.34)$ \\
\hline & $\geq 4$ times & $12,213(56.48)$ & $9802(80.26)$ & $2411(19.74)$ \\
\hline \multirow[t]{3}{*}{ Parity } & 1 child & $3678(17.01)$ & $2410(65.52)$ & $1268(34.48)$ \\
\hline & 2 children & $3750(17.34)$ & $2430(64.80)$ & $1320(35.20)$ \\
\hline & $\geq 3$ children & $14,193(65.64)$ & 8865 (62.46) & $5328(37.53)$ \\
\hline
\end{tabular}

${ }^{a}$ ANC Antenatal Care, ${ }^{\S}$ IPT Intermittent preventive treatment

IPTp utilization. The difference between our finding and previous study results is probably because antenatal attendance is very high in Malawi across the socioeconomic quintiles, providing a great opportunity to reach all pregnant women with IPTp, unlike in Nigeria where there is stock out of the drug as reported in some studies [25].

The adjusted odds ratio showed that covariates such as higher educational status and adequate antenatal visits significantly contributed to the IPTp utilization during pregnancy in Nigeria. Women with secondary and higher education had higher odds of taking IPTp-
SP compared to those with no education. This reveals that educated women are aware of the effect of malaria in pregnancy, consistent with other studies that showed educated women are more likely to take IPTpSP $[26,27]$. The number of ANC visits was significantly associated with at least one dose of IPTp-SP. This is not surprising because pregnant women are recommended to be given the drug during the ANC visits [4]. Although findings from a systematic review shows inconsistent association between the ANC attendance and the IPTp uptake [28], the possible reason of the variation is that some women attend ANC 
Table 2 Bivariate and Multivariable logistic regression of socio-demographic characteristics and risk factors among women aged 1549 years who had a live birth 2 years preceding the survey, by the intake of IPT, NDHS 2018

\begin{tabular}{|c|c|c|c|c|c|}
\hline Variable & & Crude OR(95\% CI) & $P$ value & Adjusted OR(95\% Cl) & $P$ value \\
\hline \multirow[t]{4}{*}{ Age group } & $15-24$ & 1 & & 1 & \\
\hline & $25-34$ & $1.22(1.14$ to 1.31$)$ & $<0.001$ & 1.03 (0.93 to 1.13$)$ & 0.57 \\
\hline & $35-44$ & 1.20 (1.11 to 1.30$)$ & $<0.001$ & 1.09 (0.97 to 1.23$)$ & 0.14 \\
\hline & $\geq 45$ & 0.99 (0.85 to 1.17$)$ & 0.960 & 1.07 (0.87 to 1.32 ) & 0.53 \\
\hline \multirow[t]{4}{*}{ Educational status } & No education & 1 & & 1 & \\
\hline & Primary & 1.87 (1.72 to 2.02$)$ & $<0.001$ & $1.13(1.02$ to 1.26$)$ & 0.023 \\
\hline & secondary & 2.72 (2.54 to 2.91$)$ & $<0.001$ & $1.32(1.18$ to 1.47$)$ & $<0.001$ \\
\hline & Higher & 4.21 (3.71 to 4.78 ) & $<0.001$ & 1.35 (1.14 to 1.60$)$ & $<0.001$ \\
\hline \multirow[t]{3}{*}{ Marital status } & Never married & 1 & & 1 & \\
\hline & Married & 1.01 (0.86 to 1.20$)$ & 0.890 & 1.12 (0.91 to 1.37$)$ & 0.28 \\
\hline & separated & 1.16 (0.93 to 1.45$)$ & 0.190 & 1.15 (0.88 to 1.50$)$ & 0.32 \\
\hline \multirow[t]{2}{*}{ Place of residence } & Urban & 1 & & 1 & \\
\hline & Rural & 0.52 (0.49 to 0.55$)$ & $<0.001$ & 1.05 (0.96 to 1.14$)$ & 0.28 \\
\hline \multirow[t]{5}{*}{ Wealth index } & Poorest & 1 & & & \\
\hline & Poorer & 1.37 (1.27 to 1.49$)$ & $<0.001$ & 1.01 (0.91 to 1.14) & 0.91 \\
\hline & Middle & 2.32 (2.13 to 2.52 ) & $<0.001$ & 1.36 (1.22 to 1.52$)$ & $<0.001$ \\
\hline & Richer & 3.35 (3.06 to 3.70$)$ & $<0.001$ & 1.79 (1.58 to 2.04) & $<0.001$ \\
\hline & Richest & 4.62 (4.16 to 5.12$)$ & $<0.001$ & 2.32 (1.99 to 2.72) & $<0.001$ \\
\hline \multirow[t]{6}{*}{ Region } & North central & 1 & & 1 & \\
\hline & North east & $1.20(1.10$ to 1.31$)$ & $<0.001$ & 1.83 (1.64 to 2.05$)$ & $<0.001$ \\
\hline & North west & 1.00 (0.92 to 1.09$)$ & $<0.001$ & 1.87 (1.68 to 2.07 ) & $<0.001$ \\
\hline & South east & 2.54 (2.26 to 2.85$)$ & $<0.001$ & $1.18(1.03$ to 1.35$)$ & \\
\hline & South south & 1.68 (1.50 to 1.88$)$ & $<0.001$ & 1.64 (1.42 to 1.90$)$ & $<0.001$ \\
\hline & South west & $1.33(1.20$ to 1.47$)$ & $<0.001$ & 0.61 (0.54 to 0.69$)$ & $<0.001$ \\
\hline \multirow[t]{3}{*}{$\mathrm{ANC}^{\mathrm{a}}$ visits } & No visits & 1 & & 1 & \\
\hline & $<4$ visits & 10.26 (9.31 to 11.30$)$ & $<0.001$ & 9.66 (8.75 to 10.68 ) & $<0.001$ \\
\hline & $\geq 4$ visits & 15.70 (14.51 to 16.98$)$ & $<0.001$ & 14.66 (13.42 to 16.02$)$ & $<0.001$ \\
\hline \multirow[t]{3}{*}{ Parity } & 1 child & 1 & & 1 & \\
\hline & 2 children & 0.97 (0.88 to 1.07 ) & 0.510 & 1.01 (0.90 to 1.13$)$ & 0.89 \\
\hline & $\geq 3$ children & 0.88 (0.81 to 0.94$)$ & $<0.001$ & 1.08 (0.96 t0 1.21) & 0.19 \\
\hline
\end{tabular}

${ }^{a}$ ANC: Antenatal Care

but were not given SP due to stock out [25, 29]. Due to the high correlation observed between ANC visits and IPTp in this study, the ANC variable was excluded during the decomposition analysis.

The odds of taking a dose of SP among women with high parity (three or more children) was lower in the bivariate analysis. However, the association was no longer significant after adjusting for education status, age, marital status, region, antenatal visits and wealth index. Ideally women with more children should have known the importance of IPT due to previous pregnancies. This is in consonance with a study by BouyouAkotet et al. which shows that having more than four children lowers the intake [30]. This result contradicts a study in Uganda which reported that women with more children used IPTp due to the possible exposure to the message of its significance [31]. Age, marital status and place of residence were not significant in the multiple regression but age and place of residence were significant in the univariate model.

The present study has some limitations. The cross sectional nature of the study design could not show the causal relationship between the available inequality on IPTp utilization and the factors that contributed to the inequality. In addition, all potential determinant factors of inequality were not included in the analysis. This 


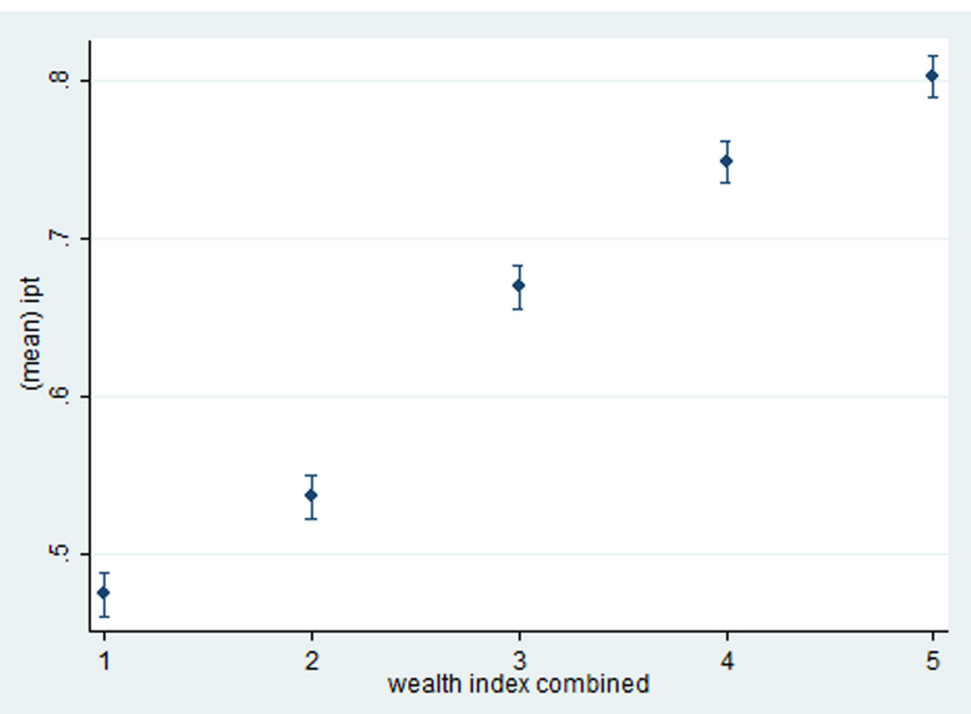

Fig. 1 Mean intake of Intermittent preventive treatment using Sulphadoxine Pyrimethamine (IPTp-SP) among pregnant women in Nigeria, by household wealth index 2018. Note: IPT refers to Intermittent Preventive Treatment

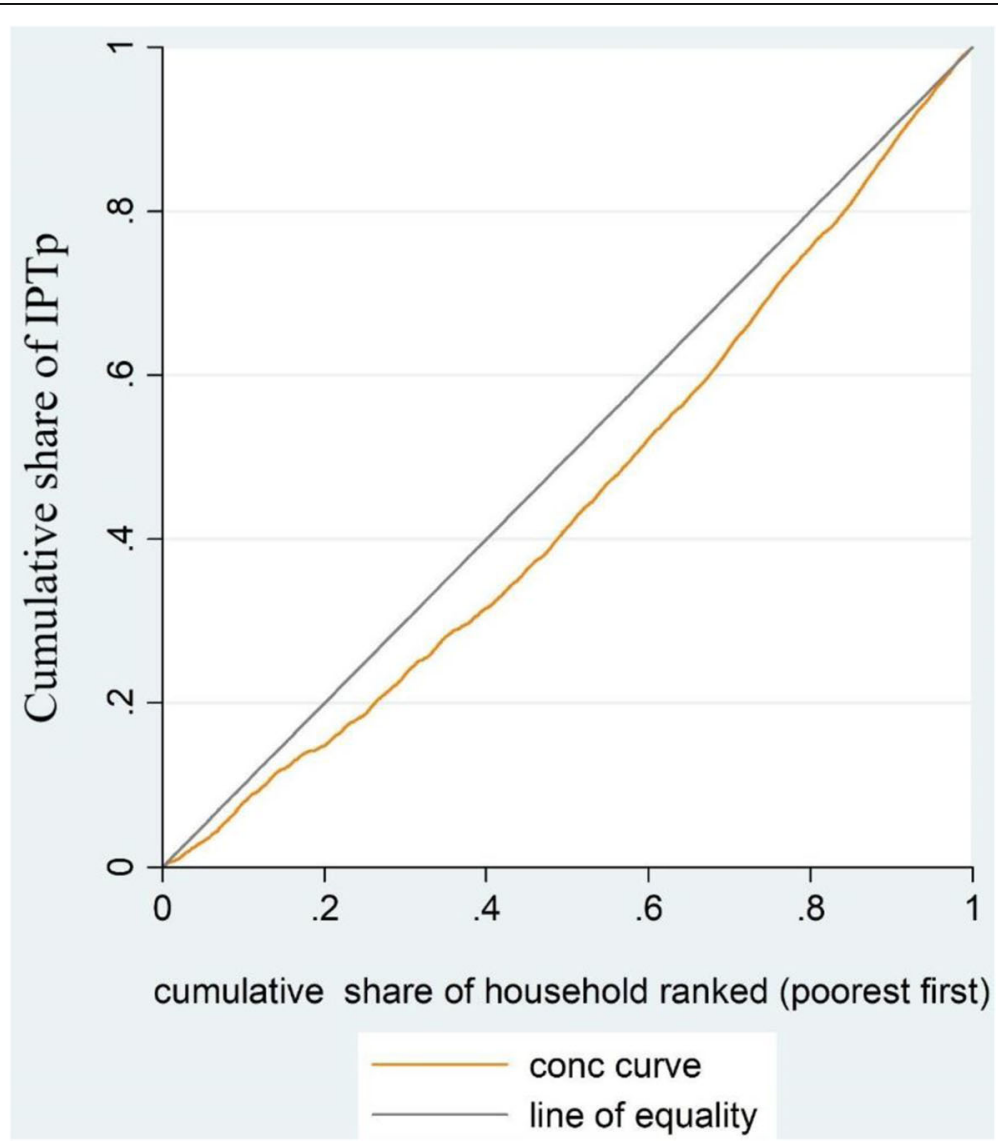

Fig. 2 Concentration curve for IPTp (antimalarial drug) among pregnant women. Note: The curve lies below the line of equality refers to pro-rich inequality 
Table 3 Decomposing socioeconomic inequality in the use of IPTp among pregnant women Nigeria 2018

\begin{tabular}{|c|c|c|c|c|c|c|}
\hline Variable & Coefficients & Mean & Elasticity & $\begin{array}{l}\text { Concentration } \\
\text { index }\end{array}$ & $\begin{array}{l}\text { Absolute } \\
\text { contribution }\end{array}$ & $\begin{array}{l}\text { Percentage } \\
\text { contribution }\end{array}$ \\
\hline Age group & & & & & & 0.69 \\
\hline $15-24$ & 1 & & & & & \\
\hline $25-34$ & 0.018 & 0.321 & 0.009 & 0.083 & 0.001 & 0.46 \\
\hline $35-44$ & 0.029 & 0.225 & 0.010 & 0.05 & 0.001 & 0.30 \\
\hline$\geq 45$ & 0.022 & 0.089 & 0.003 & -0.043 & 0.000 & -0.07 \\
\hline Educational status & & & & & & 28.66 \\
\hline No education & 1 & & & & & \\
\hline Primary & 0.131 & 0.144 & 0.030 & 0.006 & 0.000 & 0.10 \\
\hline Secondary & 0.177 & 0.397 & 0.112 & 0.282 & 0.032 & 17.76 \\
\hline Higher & 0.202 & 0.110 & .03 & 0.540 & 0.019 & 10.80 \\
\hline Marital status & & & & & & -0.18 \\
\hline Never married & 1 & & & & & \\
\hline Married & 0.054 & 0.696 & 0.059 & -0.008 & -0.000 & -0.27 \\
\hline Separated & 0.051 & 0.052 & 0.004 & 0.032 & 0.000 & 0.09 \\
\hline Place of residence & & & & & & 1.13 \\
\hline Urban & 1 & & & & & \\
\hline Rural & -0.002 & 1.541 & -0.019 & -0.105 & 0.002 & 1.13 \\
\hline Wealth Index & & & & & & 47.81 \\
\hline Poorest & 1 & & & & & \\
\hline Poorer & 0.067 & 0.192 & 0.020 & -0.399 & -0.008 & -4.50 \\
\hline Middle & 0.165 & 0.196 & 0.051 & 0.081 & 0.004 & 2.31 \\
\hline Richer & 0.221 & 0.215 & 0.074 & 0.407 & 0.030 & 17.0 \\
\hline Richest & 0.259 & 0.223 & 0.092 & 0.638 & 0.058 & 33.0 \\
\hline Region & & & & & & -9.67 \\
\hline North central & 1 & & & & & \\
\hline North east & 0.148 & 0.159 & 0.040 & -0.372 & -0.015 & -8.30 \\
\hline North west & 0.119 & 0.292 & 0.055 & -0.271 & 0.015 & -8.30 \\
\hline South east & 0.092 & 0.119 & 0.016 & 0.295 & 0.004 & 2.67 \\
\hline South south & 0.022 & 0.116 & 0.003 & 0.330 & 0.001 & 0.62 \\
\hline South west & -0.049 & 0.173 & -0.014 & 0.460 & 0.007 & 3.64 \\
\hline Parity & & & & & & 0.03 \\
\hline 1 child & 1 & & & & & \\
\hline 2 children & -0.013 & 0.165 & -0.003 & 0.120 & -0.000 & -0.26 \\
\hline$\geq 3$ children & -0.008 & 0.678 & -0.009 & 0.521 & 0.000 & 0.29 \\
\hline
\end{tabular}

might limit the comprehensiveness of our findings on the observed inequality.

\section{Conclusion}

The current study revealed considerable inequality between pregnant women in IPTp utilization in Nigeria. IPTp use is concentrated among women from the richest households which are more likely to take one or more dose compared to their counterparts. Free IPTp service expansion through targeting pregnant women from low socioeconomic status and rural area are important to reduce the available inequality. Policy makers might wish to implement other effective delivery method such as the community based delivery approach for IPTp. Further research is needed to explore the barriers of IPTp intake in Nigeria. 


\section{Supplementary Information}

The online version contains supplementary material available at https://doi. org/10.1186/s12889-020-09967-w.

Additional file 1: Supplementary Table S1. Explanatory variables included in the decomposition analysis.

\section{Abbreviations}

ANC: Antenatal care; IPTp: Intermittent preventive treatment in pregnancy; NDHS: Nigerian demographic health survey; SP: Sulphadoxine Pyrimethamine; WHO: World health organization

\section{Acknowledgements}

We are grateful for the USAID/ DHS program for their permission to access and use the survey dataset.

\section{Authors' contributions}

FM, MP, SN, HS, RM performed data extraction, data cleaning, data analysis, drafted and critically review the manuscript. All authors have read and approved the final manuscript.

\section{Funding}

This research received no specific grant from any funding agency.

\section{Availability of data and materials}

The data for this work can be accessed on the DHS website. Available at: https://dhsprogram.com/data/dataset/Nigeria_Standard-DHS_2018.cfm?flag=1.

\section{Ethics approval and consent to participate}

Permission to access the data was granted by the DHS.

\section{Consent for publication}

Not applicable.

\section{Competing interests}

The authors declare no competing interests.

\section{Author details}

${ }^{1}$ Department of Epidemiology \& Biostatistics, School of Public Health, Tehran University of Medical Sciences, Tehran, Iran. ${ }^{2}$ Department of Epidemiology \& Biostatistics, Knowledge Utilization Research Center and Community-Based Participatory-Research-Center, School of Public Health, Tehran University of Medical Sciences, Tehran, Iran. ${ }^{3}$ Knowledge Utilization Research center, University Research and Development Center, Tehran University of Medical Sciences, Tehran, Iran.

\section{Received: 11 August 2020 Accepted: 24 November 2020}

Published online: 04 December 2020

\section{References}

1. Ménard D, Clain J, Ariey F. Multidrug-resistant plasmodium falciparum malaria in the greater Mekong subregion. Lancet Infect Dis. 2018; 18(3):238-9.

2. World Health Organization. World malaria report 2018. Geneva: World Health Organization; 2018.

3. Steketee RW, Nahlen BL, Parise ME, Menendez C. The burden of malaria in pregnancy in malaria-endemic areas. J Trop Med Hyg. 2001;64(1_ suppl):28-35.

4. World Health Organization. Report of a WHO recommendation on intermittent preventive treatment of malaria in pregnancy. Geneva: World Health Organization; 2019

5. Akpa CO, Akinyemi JO, Umeokonkwo CD, Bamgboye EA, Dahiru T, Adebowale AS, et al. Uptake of intermittent preventive treatment for malaria in pregnancy among women in selected communities of Ebonyi state, Nigeria. BMC Pregnancy Childbirth. 2019;19(1):457.

6. Yusuf OB, Adeoye BW, Oladepo OO, Peters DH, Bishai D. Poverty and fever vulnerability in Nigeria: a multilevel analysis. Malar J. 2010;9(1):235.

7. Dawaki S, Al-Mekhlafi HM, Ithoi I, Ibrahim J, Atroosh WM, Abdulsalam AM, et al. Is Nigeria winning the battle against malaria? Prevalence, risk factors and KAP assessment among Hausa communities in Kano state. Malar J. 2016;15(1):351.

8. Yaya S, Uthman O, Amouzou A, Bishwajit G. Use of intermittent preventive treatment among pregnant women in sub-Saharan Africa: evidence from malaria indicator surveys. Trop Med Infect Dis. 2018;3(1):18.

9. Okethwangu D, Opigo J, Atugonza S, Kizza CT, Nabatanzi M, Biribawa C, et al. Factors associated with uptake of optimal doses of intermittent preventive treatment for malaria among pregnant women in Uganda: analysis of data from the Uganda demographic and health survey, 2016 Malar J. 2019;18(1):250

10. Whitehead M. The concepts and principles of equity and health. Health Promot Int. 1991;6(3):217-28.

11. Rutstein SO, The DHS. Wealth index: approaches for rural and urban areas. Calverton: Macro International; 2008.

12. Mathanga DP, Bowie C. Malaria control in Malawi: are the poor being served? Int J for Equity in Health. 2007;6(1):22.

13. Alawode A, Uthman OA, Yahaya I. Socio-economic inequity in accessing malaria control interventions in Nigeria: analysis of changes between 2003 and 2008. Malar J. 2012:11:S1.

14. National Population Commission (NPC) [Nigeria] and ICF Macro. Nigeria Demographic and Health Survey 2018. Abuja, Nigeria:2018,

15. Croft TN, Marshall AM, Allen CK, Arnold F, Assaf S, Balian S. Guide to DHS statistics. ICF: Rockville; 2018

16. Wagstaff A, Doorslaer VE, Watanabe N. On decomposing the causes of health sector inequalities with an application to malnutrition inequalities in Vietnam. J Econ. 2003;112(1):207-23.

17. Erreygers G. Correcting the concentration index. J Health Econ. 2009; 28(2):504-15.

18. Yiengprugsawan V, Lim LL, Carmichael GA, Dear KB, Sleigh AC. Decomposing socioeconomic inequality for binary health outcomes: an improved estimation that does not vary by choice of reference group. BMC research notes. 2010:3(1):57.

19. World Health Organization. Report on the updated policy on intermittent preventive treatment of malaria in pregnancy using sulfadoxinepyrimethamine (IPTp-SP). World Health Organization, Geneva: (2012). Available at: http://www.who.int/malaria/publications/atoz/who ipt. 2012

20. Quakyi I, Tornyigah B, Houze P, Kusi KA, Coleman N, Escriou G, et al. High uptake of intermittent preventive treatment of malaria in pregnancy is associated with improved birth weight among pregnant women in Ghana. Sci R. 2019:9(1):1-8.

21. Azizi SC, Chongwe G, Chipukuma H, Jacobs C, Zgambo J, Michelo C. Uptake of intermittent preventive treatment for malaria during pregnancy with Sulphadoxine-Pyrimethamine (IPTp-SP) among postpartum women in Zomba District, Malawi: a cross-sectional study. BMC pregnancy childbirth. 2018;18(1):108

22. Were $V$, Buff AM, Desai M, Kariuki S, Samuels A, Phillips-Howard P, et al. Trends in malaria prevalence and health related socioeconomic inequality in rural western Kenya: results from repeated household malaria cross-sectional surveys from 2006 to 2013. BMJ Open. 2019; 9(9):e033883.

23. Buh A, Kota K, Bishwajit G, Yaya S. Prevalence and associated factors of taking intermittent preventive treatment in pregnancy in Sierra Leone. Trop Med Infect Dis. 2019:4(1):32.

24. Amankwah S, Anto F. Factors associated with uptake of intermittent preventive treatment of malaria in pregnancy: a cross-sectional study in private health facilities in Tema Metropolis. Ghana. J Trop Med. 2019;2019.

25. Ameh S, Owoaje E, Oyo-Ita A, Kabiru CW, Akpet OEO, Etokidem A, et al. Barriers to and determinants of the use of intermittent preventive treatment of malaria in pregnancy in Cross River state, Nigeria: a cross-sectional study. BMC Pregnancy Childbirth. 2016;16(1):99.

26. Addai-Mensah O, Annani-Akollor ME, Fondjo LA, Sarbeng K, Anto EO, Owiredu E-W, et al. Regular antenatal attendance and education influence the uptake of intermittent preventive treatment of malaria in pregnancy: a cross-sectional study at the university hospital, Kumasi, Ghana. J Trop Med. 2018;2018.

27. Peter AO. Effect of intermittent preventive treatment of malaria on the outcome of pregnancy among women attending antenatal clinic of a new Nigerian teaching hospital, ado-Ekiti. Nigerian medical journal: journal of the Nigeria Medical Association. 2013;54(3):170.

28. Hill J, Hoyt J, van Eijk AM, D'Mello-Guyett L, ter Kuile FO, Steketee $R$, et al. Factors affecting the delivery, access, and use of interventions to prevent 
malaria in pregnancy in sub-Saharan Africa: a systematic review and metaanalysis. PLoS Med. 2013;10:7.

29. Amoran OE, Ariba AA, lyaniwura CA. Determinants of intermittent preventive treatment of malaria during pregnancy (IPTp) utilization in a rural town in Western Nigeria. Reprod Health. 2012;9(1):12.

30. Bouyou-Akotet MK, Mawili-Mboumba DP, Kombila M. Antenatal care visit attendance, intermittent preventive treatment and bed net use during pregnancy in Gabon. BMC Pregnancy Childbirth. 2013;13(1):52.

31. Wanzira H, Katamba H, Okullo AE, Rubahika D. The challenge of using intermittent preventive therapy with sulfadoxine/pyrimethamine among pregnant women in Uganda. Malar J. 2016;15(1):401.

\section{Publisher's Note}

Springer Nature remains neutral with regard to jurisdictional claims in published maps and institutional affiliations.

Ready to submit your research? Choose BMC and benefit from:

- fast, convenient online submission

- thorough peer review by experienced researchers in your field

- rapid publication on acceptance

- support for research data, including large and complex data types

- gold Open Access which fosters wider collaboration and increased citations

- maximum visibility for your research: over $100 \mathrm{M}$ website views per year

At BMC, research is always in progress.

Learn more biomedcentral.com/submissions 